\title{
A Decision Making Model for the Evaluation of Supply Chain Execution and Management Systems
}

\author{
Sinan Apak ${ }^{1 *}$, Özalp Vayvay ${ }^{2}$, Orhan Feyzioğlu ${ }^{3}$ \\ ${ }^{1}$ Department of Industrial Engineering, Maltepe University, 34857, İstanbul, Turkey \\ ${ }^{2}$ Department of Industrial Engineering, Marmara University, 34722, İstanbul, Turkey \\ ${ }^{3}$ Department of Industrial Engineering, Galatasaray University, 34357, İstanbul, Turkey \\ E-mail: sinanapak@maltepe.edu.tr, ozalp@marmara.edu.tr, orhanfeyzioglu@gmail.com
}

\author{
Received 25 March 2011 \\ Accepted 28 October 2012
}

\begin{abstract}
A Supply Chain Execution and Management (SCEM) system is an enterprise application that integrates all of the necessary supply chain functions into a single system. These functions range from common ones such as warehouse and transportation management to less known ones such as demand management. In order to execute and manage the supply chain processes successfully, organisations need a comprehensive evaluation approach to determine the most suitable system. The evaluation of an SCEM system involves numerous decision making criteria. Moreover, it is usually characterised with uncertainty and vagueness since it is very difficult to rate SCEM system alternatives with exact terms. To cope with this problem, a fuzzy logic-based approach is developed in this study. This approach main integrates the Fuzzy Analytic Hierarchy Process to weight the decision criteria and the Fuzzy Technique for Order Preference by Similarity to Ideal Solution to rate alternatives. A real life example is provided to demonstrate the capability of the proposed approach.
\end{abstract}

Keywords: Supply Chain Execution and Management System, F-MADM, F-AHP, F-TOPSIS.

\section{Introduction}

The main objective of this paper is to propose a systematic evaluation model to help the members of supply chains for the selection of the most appropriate Supply Chain Execution and Management (SCEM) system among a set of available alternatives. The study considers supply chain modules as criteria while evaluating SCEM systems. These criteria are derived from the literature and an industrial analysis. According to our knowledge, the approach of considering modules as criteria has not been followed before. The best SCEM system selection problem is both a Multi-Attribute Decision Making (MADM) problem where many criteria should be considered in the decision-making, and a problem containing subjectivity, uncertainty and ambiguity in the assessment process. Therefore, this study makes use of a MADM method to determine the importance weights of evaluation criteria, and fuzzy logic to obtain the performance ratings of the feasible alternatives in linguistic values.

Supply chain is a field where structural changes occur frequently. Uncertainty arises and continuous planning is required due to those changes in the processes of the supply chain. Therefore supply chain management (SCM) is coming under scrutiny to try to achieve this competitive advantage as it provides many opportunities for reducing operating costs and improving customer service and satisfaction. ${ }^{1}$ Hence, dynamic and integrated management systems are necessary to cope with this continuous change. Managers are required to choose the proper level of integration for particular relationships in the supply chain and the appropriate degree of information 
sharing. ${ }^{2}$ An SCEM system is a business system that integrates a company's internal resources to manage and work with the external supply chain. In this sense, correct decisions would be taken with the right management systems. Based on their organisational structure and business diversity, firms use management systems to not only identify correct investments and reduce costs, but also to increase their efficiency. This organisational nature of supply chain makes systems evaluation, selection, and implementation more complex. The basic reason to use an SCEM system is to support all planning and execution functions required for the supply chain. ${ }^{3,4}$ The major aims of SCEM system are to reduce supply chain risk, reduce production costs, maximise revenue, improve customer service, optimise inventory levels, business processes, and cycle times, and result in increased competitiveness, customer satisfaction and profitability. ${ }^{5,6}$ These systems also provide platforms for fast and reliable operations between trading partners, regardless of any physical barriers.

The supply chain software market has risen to the challenge of complexity in the supply chain by making its SCM solutions more and more complex, often to the detriment of the very efficiency and cost-effectiveness that supply chain users need. Such system packages cost hundreds of thousands or even millions of dollars, making purchasing a system solution a high expenditure activity that consumes a significant portion of companies' capital budgets. ${ }^{7}$ Companies have trouble finding the return on investment for these massive supply chain projects. The evaluation of those systems is a very complicated and costly task, and their inappropriate use may lead the firm to bankruptcy. Consequently, the selection of those management systems involves a complex decision process, and detailed analysis supported with analytical methods is needed. Hence, firms should evaluate their SCEM system with appropriate criteria and implement it properly to increase performance and efficiency. In addition, with new standards, processes, and a continuously developing technology, the evaluation process becomes more elaborative and dynamic. ${ }^{8}$

Selecting the right solution is an exhausting process for companies. Therefore, evaluating a system that meets the requirements needs a full examination of many conflicting factors, which is a difficult task. This has led researchers to investigate better ways of evaluating and selecting those systems. Early studies show us that the selection processes of these systems have been studied many times considering different methodologies and criteria. SCEM systems are relatively related to ERP and SCM systems. Hence, we have to review those system evaluation approaches and criteria to better understand the originality of this paper. A number of methods have been applied to ERP, SCM or other information system selections, including scoring, ranking, mathematical optimisation, and multicriteria decision analysis. ${ }^{5,9-16}$ However, an SCEM system evaluation problem is not considered in a module-based multi-criteria decision making framework in the existing literature. This paper models a MADM method for SCEM system evaluation. The method is an F-AHP \& F-TOPSIS integrated decision-making approach. A fuzzy logic approach was adopted due to subjective considerations of human judgments. A multistage MADM method was used, including F-AHP to determine the relative weights of evaluation criteria, and F-TOPSIS to rank the alternatives.

The rest of the paper is structured as follows: We present a brief literature review on SCEM system modules in Section 2. In Section 3, we provide the details of our evaluation approach which integrates FAHP and F-TOPSIS methods. How the proposed approach can be used to evaluate real world examples is discussed in Section 4. Finally, the last section contains some conclusions and suggestions.

\section{Literature Review on SCEM Systems Modules}

We conducted an extensive review of the current literature on supply chain execution and management system modules. Most of the reviewed articles focus on the different types of measures, such as strategic, tactical and operational, tangible, intangible, financial and non-financial. Some articles focus on the techniques and tools used in evaluating information system projects and investments. The articles that mention the modules that are used in supply chain management are given in Table 1. 
Apak et al.

Table 1 Supply Chain Modules

\begin{tabular}{|c|c|c|c|c|c|c|c|c|c|c|c|c|c|c|c|c|c|c|c|c|}
\hline $\begin{array}{l}\text { Modules and sub-modules } \\
\text { /Authors }\end{array}$ & 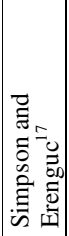 & 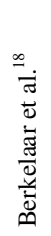 & $\stackrel{a^{2}}{\stackrel{\infty}{0}}$ & 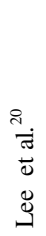 & 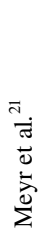 & 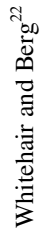 & 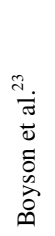 & 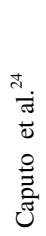 & 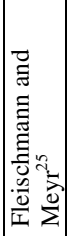 & 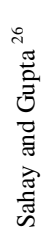 & 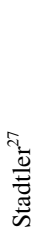 & 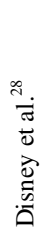 & 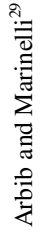 & 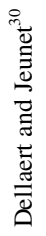 & 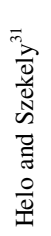 & 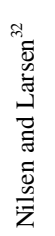 & 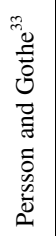 & 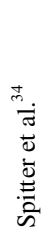 & 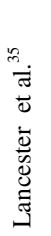 & 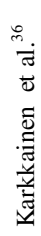 \\
\hline Accounting standards & & & & & & $\bullet$ & & & & & & & & & & & & & & \\
\hline Advanced planning system & & & & $\bullet$ & & $\bullet$ & & & & $\bullet$ & $\bullet$ & $\bullet$ & & & & & & $\bullet$ & & \\
\hline Available to promise & & & & & $\bullet$ & & $\bullet$ & & $\bullet$ & & $\bullet$ & & & & & & $\bullet$ & & & \\
\hline Bar-coding & & & & & & & $\bullet$ & & & & & & & $\bullet$ & & & & & $\bullet$ & \\
\hline Catalogue management & & & & & & & & & & & & & & & & & & & $\bullet$ & \\
\hline Collaboration & & & & & & & & & & $\bullet$ & $\bullet$ & $\bullet$ & & & & & & & & $\bullet$ \\
\hline Customer service & & & & & & & & & & $\bullet$ & & $\bullet$ & & & & & & & $\bullet$ & \\
\hline Decentralisation & & & & & & & & & & & $\bullet$ & & & & & & & & & \\
\hline Delivery coordination & & & & & & & & & & & & & & & & & & & & $\bullet$ \\
\hline Demand fulfilment & & & $\bullet$ & & $\bullet$ & & & & $\bullet$ & & $\bullet$ & & & & & & $\bullet$ & & & \\
\hline Demand planning & & & & & $\bullet$ & & & & & $\bullet$ & $\bullet$ & & & & & & & $\bullet$ & & \\
\hline Distribution planning & $\bullet$ & & & $\bullet$ & $\bullet$ & & & & & $\bullet$ & & & & $\bullet$ & & & $\bullet$ & & & $\bullet$ \\
\hline Event-based planning & & & & & & & & & & & $\bullet$ & & & & & & & & & \\
\hline Finance control & & & & & & & & & & & & & & & $\bullet$ & & & & & \\
\hline Fleet size & & & & & & & & $\bullet$ & & & & & & & & & & & & \\
\hline Forecasting & & & & & & & & & & & & $\bullet$ & & & & & & & & \\
\hline Human resources & & & & & & & & & & & & & & & $\bullet$ & & & & & \\
\hline Inventory control & & & & & & & & & & & & & & & & $\bullet$ & & & $\bullet$ & \\
\hline Inventory management & & & & & & & $\bullet$ & & & $\bullet$ & & & & & & $\bullet$ & & & $\bullet$ & \\
\hline Lead times & & $\bullet$ & & & & & & & & & & & & & $\bullet$ & & & $\bullet$ & & \\
\hline Logistics Planning & & & & & & & & $\bullet$ & & & & & & & & & & & & \\
\hline Lot sizing optimisation & & $\bullet$ & & & & & & & & & & & & & $\bullet$ & & & & & \\
\hline Marketing & & & & & & & & & & & & & & & & & & & $\bullet$ & \\
\hline Master planning & $\bullet$ & $\bullet$ & $\bullet$ & & $\bullet$ & & & & & & $\bullet$ & & $\bullet$ & & & & $\bullet$ & $\bullet$ & & \\
\hline Material handling & & & & & & & & & & & & & & & $\bullet$ & & & & & \\
\hline Material requirement planning & & & & & $\bullet$ & & $\bullet$ & & & & $\bullet$ & & & $\bullet$ & $\bullet$ & & & $\bullet$ & & \\
\hline Transportation control & & & & & & & & & & & & & & & $\bullet$ & & & & & \\
\hline Order flow & & & & & & & & & & & & & & & $\bullet$ & & & & & \\
\hline Order promising & & & $\bullet$ & & & & & & $\bullet$ & $\bullet$ & & & $\bullet$ & & $\bullet$ & & $\bullet$ & $\bullet$ & & \\
\hline Order tracking & & & & & & & & & & & & & & & $\bullet$ & & & & & $\bullet$ \\
\hline Procurement & & & & $\bullet$ & & & & & & & & & & & & & & & & \\
\hline Production planning & $\bullet$ & & & & $\bullet$ & & & & & & $\bullet$ & & & & & & & $\bullet$ & & \\
\hline Purchasing & & & & $\bullet$ & & & $\bullet$ & & & & & & & & & $\bullet$ & & & & \\
\hline Real time information & & & & & & & & & & & & & & & $\bullet$ & & & & & \\
\hline Route Planning & & & & & & & & & & & & & & & $\bullet$ & & & & & \\
\hline Scheduling & & $\bullet$ & & $\bullet$ & $\bullet$ & & & & & $\bullet$ & $\bullet$ & $\bullet$ & $\bullet$ & & & & $\bullet$ & & & \\
\hline Service demand & & & & & & & & $\bullet$ & & & & & & & & & & & & \\
\hline Shortage planning & & & & & & & & & & & & & $\bullet$ & & & & & $\bullet$ & & \\
\hline Shipment planning & & & & & & & & & & & & & $\bullet$ & & & & & & & \\
\hline Supplier management & & & & & & & & & & $\bullet$ & & & & & & & & & & \\
\hline Supply chain planning & & & & $\bullet$ & & & & & & $\bullet$ & & & & & & & & & $\bullet$ & $\bullet$ \\
\hline Supply chain design & & & & & & & & & & $\bullet$ & & & & & & & & & & \\
\hline Strategic network planning & & & & & $\bullet$ & & & & & & & & & & & & & & & \\
\hline Transportation planning & $\bullet$ & & & & $\bullet$ & & & $\bullet$ & & & & & & & & & & $\bullet$ & & \\
\hline Transaction process & & & & & & & & & & & & & & & $\bullet$ & & & & $\bullet$ & $\bullet$ \\
\hline Uncertainty & & & & & & & & & & & $\bullet$ & & & & $\bullet$ & & & & & \\
\hline Vehicle routing & & & & & & & & $\bullet$ & & & & & & & & & & & & \\
\hline Vehicle type & & & & & & & & $\bullet$ & & & & & & & & & & & & \\
\hline
\end{tabular}




\section{Methodology of the Research}

MADM is a methodology that helps decisionmakers when making preference decisions regarding a finite set of available alternatives characterised by multiple potentially conflicting attributes. ${ }^{37}$ The typical multi-attribute evaluation problem focuses on a set of feasible alternatives and considers more than one criterion to determine a priority ranking for alternative implementation. MADM involves three phases; firstly, the information about attribute weights and attribute values needs collecting; secondly, weighted aggregation of the attribute values across all attributes for each alternative is performed to obtain an overall value; thirdly, the overall values are ordered to obtain the best alternatives. ${ }^{38}$ In MADM, each criterion needs to be compared with other criteria in terms of their relative importance for achieving the overall objective of the problem. ${ }^{39}$ However, in many cases, the preference model of the human decision maker is uncertain, and it is relatively difficult to provide exact numerical values for the comparison ratios. To cope with uncertain judgments expressions, the ratios were fuzzy sets, which incorporate the vagueness of human thinking. Linguistic variables are very useful in dealing with uncertain and inaccurate factors involved in complex group decision situations. ${ }^{40}$ In fuzzy decision-making, alternatives can be evaluated by using quantitative and/or qualitative variables. As fuzzy models can use both of these types of variable, they are more flexible than other decision-making models.

\subsection{The Fuzzy Logic}

The underlying logic of linguistic approach is that the truth values are fuzzy sets and the rules of inference are approximate rather than exact. Fuzzy logic allows us to make rational decisions in an environment of uncertainty, fuzziness and imprecision without losing the richness of verbal judgment. We consider a triangular type of fuzzy number as a well-known application. The membership function for a triangular fuzzy number (TFN) is the triangular shape, which can be presented by a triplet $(l, m, u)$, indicating the lower limit of support, the mode (core) and the upper limit of support. They are the most common fuzzy numbers, and the main reason for using them is that decision makers find them intuitively easy to use. ${ }^{39}$ TFN's membership function is defined as:

$$
\mu_{\tilde{A}}(x)= \begin{cases}\frac{x-l}{m-l}, & l \leq x \leq m \\ \frac{u-x}{u-m}, & m \leq x \leq u \\ 0, & \text { otherwise }\end{cases}
$$

where $l \leq m \leq u ; l$ and $u$ stand for the lower and upper value of the support of $A$, respectively; $m$ is the most possible value of fuzzy number $A$. When $l=m=u$, it is a non-fuzzy number by convention. ${ }^{10} \mathrm{We}$ assume that $\infty<l \leq m \leq u<\infty$. The operational laws of two TFNs

$\tilde{A}_{1}=\left(l_{1}, m_{1}, u_{1}\right)$ and $\tilde{A}_{2}=\left(l_{2}, m_{2}, u_{2}\right)$ as shown:

Fuzzy number addition and subtraction:

$\tilde{A}_{1} \mp \tilde{A}_{2}=\left(l_{1}, m_{1}, u_{1}\right) \mp\left(l_{2}, m_{2}, u_{2}\right)=\left(l_{1} \mp l_{2}, m_{1} \mp m_{2}, u_{1} \mp u_{2}\right)$

Fuzzy number multiplication:

$\tilde{A}_{1} \otimes \tilde{A}_{2}=\left(l_{1}, m_{1}, u_{1}\right) \otimes\left(l_{2}, m_{2}, u_{2}\right)=\left(l_{1} \times l_{2}, m_{1} \times m_{2}, u_{1} \times u_{2}\right)$

Fuzzy number inversion:

$\tilde{A}^{-1}=(l, m, u)^{-1} \cong(1 / u, 1 / m, 1 / l)$ for $l, m, u>0$

Overall, the SCEM system evaluation procedure contains subjective judgments including vague and imprecise information. These kinds of processes make fuzzy logic necessary for SCEM system evaluation. Fuzzy MADM methods are used in this paper to compute ratings for vendors.

\subsection{Extended F-AHP and F-TOPSIS Integrated Approach}

The proposed approach incorporates the following elements: it can handle uncertain information, which is gathered in linguistic terms; decision making can be conducted by the decision makers in an integrated hierarchy; and alternatives are evaluated along a hierarchy. The F-AHP phase applies the fuzzy set theory to construct the pair-wise comparisons of the AHP by transforming linguistic judgments into fuzzy numbers to calculate and integrate the weights of the criteria. These weights are then used to rank the alternatives in the F-TOPSIS phase. An AHP and 
TOPSIS integrated model has been applied to various decision-making problems. ${ }^{41-42}$

\subsubsection{F-AHP Phase}

The AHP has been widely used for the evaluation of software packages ${ }^{43}$, and was first introduced by Saaty ${ }^{44}$, making it one of the most used multi-criteria decision making methods. AHP incorporates the evaluations of all decision makers into a final decision by pair-wise comparisons of the alternatives, without having to elicit their utility functions on subjective and objective criteria. ${ }^{44}$ Many researchers have studied on software evaluation applications of fuzzy $\mathrm{AHP}^{43}$ and several models are constructed in relation with the evaluation of supply chain systems. F-AHP has been used to help experts to evaluate a knowledge portal ${ }^{49}$, to evaluate IT departments ${ }^{50}$, to select a suitable ERP system for the textile industry ${ }^{11}$, to classify inventories $^{51}$, to estimate the relative importance strategic factors involved in the decision making process of adopting third party e-markets ${ }^{52}$, and to develop radio frequency identification technology in logistics and supply chain management. ${ }^{42}$

The F-AHP methodology steps:

Step 1. Structure problem hierarchy: The first step of the methodology is to construct a problem into a hierarchy, including a goal, set of criteria, and set of alternatives. The general hierarchy structure of F-AHP is shown as Figure 1. The highest level of the hierarchy (level 1) consists of only one element, an object or a goal, that the decision maker wants to reach. The lower levels (level 2) of the hierarchy contain criteria (attributes), which contribute to the goal. The process may continue down to criteria that are more detailed at level 3. The last level of the hierarchy, level 4, includes decision alternatives, which are to be evaluated in terms of the criteria of the upper level.

Step 2. Construct pair-wise comparisons: It is very difficult to reasonably express those situations that are overtly complex or hard to define with conventional quantification; therefore, the notion of a linguistic variable is necessary in such situations. A linguistic variable is a variable whose values are words or sentences in a natural or artificial language. In this paper, we use the linguistic scales shown in Table 2.

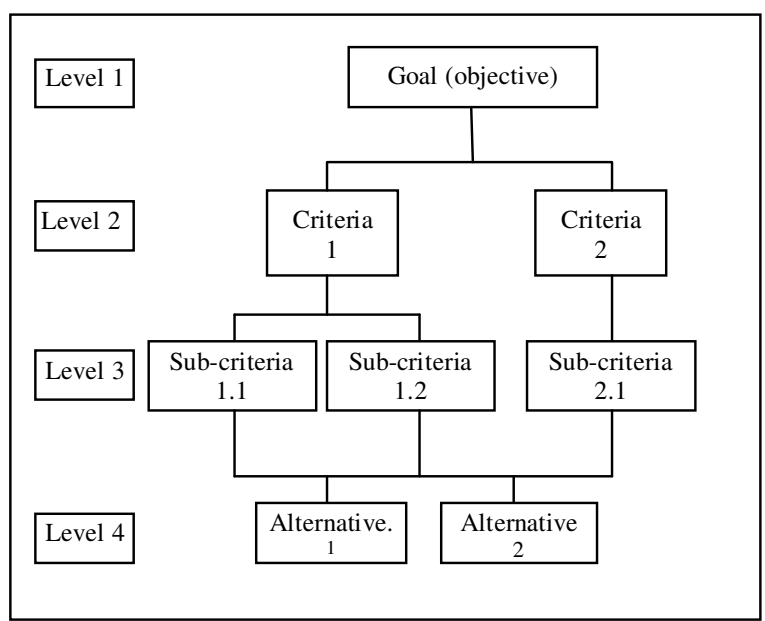

Figure 1 The construct of fuzzy pair-wise comparison matrices

Step 3. Transform Linguistic Judgments into Fuzzy Numbers: After the decision makers complete the assigning of linguistic judgment in the pairwise comparison matrix in step 2, the linguistic judgment is transformed into a fuzzy number. In this paper, the computational technique is based on the fuzzy numbers defined in Table 2. Here, each membership function (scale of fuzzy number) is defined by three parameters of the symmetrical triangular fuzzy number: the left point, middle point and right point of the range over which the function is defined.

Table 2 Membership function of linguistic scale

\begin{tabular}{clc}
\hline $\begin{array}{l}\text { Fuzzy } \\
\text { number }\end{array}$ & Linguistic scales & $\begin{array}{l}\text { Scale of fuzzy } \\
\text { number }\end{array}$ \\
\hline$\tilde{1}$ & Equally important (Eq) & $(1,1,3)$ \\
$\tilde{2}$ & Weakly important (Wk) & $(1,3,5)$ \\
$\tilde{3}$ & Essentially important (Es) & $(3,5,7)$ \\
$\tilde{4}$ & Very strongly important (Vs) & $(5,7,9)$ \\
$\tilde{5}$ & Absolutely important (Ab) & $(7,9,9)$ \\
\hline
\end{tabular}

Linguistic terms are assigned to the pairwise comparisons by asking which is the more important of each two criteria, such as:

$$
A=\left[\begin{array}{cccc}
1 & \tilde{b}_{12} & \cdots & \tilde{b}_{1 n} \\
\tilde{b}_{21} & 1 & \cdots & \tilde{b}_{2 n} \\
\vdots & \vdots & \ddots & \vdots \\
\tilde{b}_{n 1} & \tilde{b}_{n 2} & \cdots & 1
\end{array}\right]
$$


Apak et al.

$$
=\left[\begin{array}{cccc}
1 & \tilde{b}_{12} & \cdots & \tilde{b}_{1 n} \\
1 / \tilde{b}_{12} & 1 & \cdots & \tilde{b}_{2 n} \\
\vdots & \vdots & \ddots & \vdots \\
1 / \tilde{b}_{1 n} & 1 / \tilde{b}_{2 n} & \cdots & 1
\end{array}\right]
$$

where

$$
\tilde{b_{i j}}= \begin{cases}\tilde{1}, \tilde{3}, \tilde{5}, \tilde{7}, \tilde{9} & \text { criterion } i \text { is relativelymore important than criterion } j, \\ 1 & i=j, \\ \tilde{1}^{-1}, \tilde{3}^{-1}, \tilde{5}^{-1}, \tilde{7}^{-1}, \tilde{9}^{-1} & \text { criterion } i \text { is relatively less important than criterion } j\end{cases}
$$

Triangular fuzzy numbers are substituted into the pair-wise comparison matrix to deal with criteria measurements and determine the fuzzy consensus problem in judgment. ${ }^{45,46}$ A geometric mean is used for aggregating the judgments of each group member found in pairwise comparison matrices. This approach is used when individuals are willing to relinquish their own preferences for the good of the organisation. ${ }^{47}$

From each decision maker's questionnaire results, we establish fuzzy weights for control criteria according to the membership functions. The geometric mean of the decision makers' evaluations forms the consensus in this paper, and is established as follows:

$$
\begin{aligned}
& \tilde{a}_{i j}=\left(l_{i j}, m_{i j}, u_{i j}\right) \\
& l_{i j} \leq m_{i j} \leq u_{i j} \text { and } l_{i j}, m_{i j}, u_{i j} \in[1 / 9,1] \cup[1,9] . \\
& l_{i j}=\left(\prod_{k=1}^{n} B_{i j k}\right)^{1 / n}, \\
& m_{i j}=\left(\prod_{k=1}^{n} B_{i j k}\right)^{1 / n}, \\
& u_{i j}=\left(\prod_{k=1}^{n} B_{i j k}\right)^{1 / n} .
\end{aligned}
$$

where $B_{i j k}$ represents a judgment of decision maker $k$ for the relative importance of two criteria, $i-j$.

Step 4. Check the Consistency: Different methods for computing the consistency ratio can be found in the literature; however, the algorithm proposed by Mikhailov $^{48}$ is preferred. According to this algorithm, if the eigenvalue computed for pairwise comparison matrices consisting of fuzzy numbers is between 0 and 1 , the matrix is assumed to be consistent, and if the

eigenvalue is less than 0 the matrix is assumed to be inconsistent.

Step 5. Calculate the Fuzzy Weight Vectors: We define the fuzzy geometric mean and fuzzy weights of each criterion as follows:

$$
\begin{gathered}
\tilde{r}_{i}=\left(\tilde{a}_{i 1} \otimes \tilde{a}_{i 2} \otimes \ldots \otimes \tilde{a}_{i n}\right)^{1 / n}, \\
\tilde{w}_{i}=\tilde{r}_{i} \otimes\left(\tilde{r}_{1} \oplus \ldots \oplus \tilde{r}_{n}\right)^{-1},
\end{gathered}
$$

where $\tilde{a}_{i n}$ is fuzzy comparison value of criterion $i$ to criterion $n$; thus, $\tilde{r}_{i}$ is geometric mean of fuzzy comparison value of criterion $i$ to each criterion;, $\tilde{w}_{i}$ is the fuzzy weight of the $i^{\text {th }}$ criterion, and can be indicated by a TFN, $\tilde{w}_{i}=\left(l w_{i}, m w_{i}, u w_{i}\right)$. Here $l w_{i}$, $m w_{i}$ and $u w_{i}$ stand for the lower, middle and upper values of the fuzzy weight of the $i^{\text {th }}$ criterion. Calculations are performed for each criterion (for both the main and secondary criteria), then the global weights are found by multiplying the main criterion fuzzy weight to each secondary-criterion weight that is connected to the main criterion fuzzy weight. The fuzzy weights of alternatives derived from the F-AHP process are used as parameters for goal constraints in the FTOPSIS.

\subsubsection{F-TOPSIS Phase}

The basic principle of this approach is that the chosen alternative should have the shortest distance from the ideal solution and farthest distance from the negative-ideal solution. ${ }^{53}$ TOPSIS views a MADM problem with $t$ alternatives as a geometric system, with $t$ points in the n-dimensional space $^{54}$ The implementation of an enhanced TOPSIS model is based on the concept that the chosen SCEM system alternatives should be the shortest distance from the ideal solution and the farthest from the negative-ideal solution. The advantages of using the F-TOPSIS concept have been highlighted by its intuitively appealing logic, its simplicity and comprehensibility, its computational efficiency, its ability to measure the relative performance of the alternatives with respect to individual or all evaluation criteria in a simple mathematical form, and its applicability in solving various practical MADM problems. ${ }^{55,56}$

F-TOPSIS methodology steps:

Step 1. Determine the weights of the evaluation criteria: the overall weights of various criteria have 
been considered with the F-AHP method to conduct the F-TOPSIS phase.

Step 2. Choose the appropriate linguistic variables for the alternatives with respect to criteria: The linguistic variables are described by TFNs, such as $\tilde{x}_{i j}=\left(a_{i j}, b_{i j}, c_{i j}\right)$ in Table 3 .

Table 3 Linguistic variables for the preference rating of alternatives

\begin{tabular}{|c|c|}
\hline Linguistic variable & $\begin{array}{l}\text { Corresponding triangular fuzzy } \\
\text { numbers }\end{array}$ \\
\hline Very poor (VP) & $(0.0,0.0,0.2)$ \\
\hline Poor $(\mathrm{P})$ & $(0.0,0.2,0.4)$ \\
\hline Fair (F) & $(0.3,0.5,0.7)$ \\
\hline $\operatorname{Good}(\mathrm{G})$ & $(0.6,0.8,1.0)$ \\
\hline Very Good (VG) & $(0.8,1.0,1.0)$ \\
\hline
\end{tabular}

Then, the fuzzy calculations are performed in a fuzzy decision matrix as follows:

$$
\begin{aligned}
& \begin{array}{llll}
C_{1} & C_{2} & \ldots & C_{n}
\end{array} \\
& \tilde{D}=A_{2} \quad\left[\begin{array}{llll}
\tilde{x}_{11} & \tilde{x}_{12} & \cdots & \tilde{x}_{1 n} \\
\tilde{x}_{21} & \tilde{x}_{22} & \cdots & \tilde{x}_{2 n}
\end{array}\right], i=1,2, \ldots, m, j=1,2, \ldots, n \\
& A_{m}\left[\begin{array}{llll}
\vdots & \vdots & \ddots & \vdots \\
\tilde{x}_{m 1} & \tilde{x}_{m 2} & \cdots & \tilde{x}_{m n}
\end{array}\right] \\
& \tilde{x}_{i j}=\frac{1}{k}\left(\tilde{x}_{i j}^{1}+\tilde{x}_{i j}^{2}+\ldots+\tilde{x}_{i j}^{k}\right)
\end{aligned}
$$

where $\tilde{x}_{i j}^{k}$ is the rating of alternative $A_{i}$ with respect to criteria $C_{j}$ evaluated by decision maker $k$, and $\tilde{x}_{i j}^{k}=\left(a_{i j}^{k}, b_{i j}^{k}, c_{i j}^{k}\right)$.

Step 3. Construct the fuzzy decision matrix and the normalised fuzzy decision matrix: The aim here is to transform the various criteria scales into a comparable scale. Therefore, we can obtain the normalised fuzzy decision matrix denoted by $\tilde{R}$ :

$$
\tilde{R}=\left[\tilde{r}_{i j}\right]_{m \times n} i=1,2, \ldots, m ; j=1,2, \ldots, n .
$$

The normalisation process can then be performed using the following formula:

$$
\begin{gathered}
\tilde{r}_{i j}=\left(\frac{a_{i j}}{c_{j}^{*}}, \frac{b_{i j}}{c_{j}^{*}}, \frac{c_{i j}}{c_{j}^{*}}\right), \\
c_{j}^{*}=\max _{i} c_{i j} .
\end{gathered}
$$

Step 4. Construct the weighted normalised fuzzy decision matrix: The normalisation method mentioned above is used to preserve the property to which the ranges of normalised TFNs belong [0,1]. Considering the different importance of each criterion, we can construct the weighted normalised fuzzy decision matrix as:

$$
\tilde{V}=\left[\tilde{v}_{i j}\right]_{m \times n}, i=1,2, \ldots, m ; j=1,2, \ldots, n .
$$

and

$$
\tilde{v}_{i j}=\tilde{r}_{i j} \times \tilde{w}_{j}
$$

as well as $\tilde{w}_{j}$ global TFN weights, as defined in Eq.

(12) that are calculated in F-AHP phase.

Step 5. Determine the fuzzy positive-ideal solution (FPIS) and fuzzy negative-ideal solution (FNIS): According to the weighted normalised fuzzy decision matrix, we know that the elements $\tilde{v}_{i j}$ are normalised positive TFNs and their ranges belong to the closed interval [0,1]. Therefore, we can define the FPIS $A^{*}$ and $A^{-}$using the following formulae:

$$
A^{*}=\left(\tilde{v}_{1}^{*}, \tilde{v}_{2}^{*}, \ldots, \tilde{v}_{n}^{*}\right)
$$

and

$$
A^{-}=\left(\tilde{v}_{1}^{-}, \tilde{v}_{2}^{-}, \ldots, \tilde{v}_{n}^{-}\right)
$$

where $\tilde{v}_{j}^{*}=w_{j} \times(1,1,1)$ and $\tilde{v}_{j}^{-}=w_{j} \times(0,0,0)$ for all $j=1$, $2, \ldots, n$.

Step 6. Calculate the distance of each alternative from FPIS and FNIS: The distances $\left(d_{i}^{*}\right.$ and $\left.d_{i}^{-}\right)$of each alternative from $A^{*}$ and $A^{-}$can be currently calculated by the vertex method, which is calculated as follows:

Let $\tilde{a}=\left(a_{1}, a_{2}, a_{3}\right)$ and $\tilde{b}=\left(b_{1}, b_{2}, b_{3}\right)$ be two triangular fuzzy numbers,

$$
d(\tilde{a}, \tilde{b})=\sqrt{\frac{1}{3}\left[\left(a_{1}-b_{1}\right)^{2}+\left(a_{2}-b_{2}\right)^{2}+\left(a_{3}-b_{3}\right)^{2}\right]}
$$

then,

$$
d_{i}^{*}=\sum_{j=1}^{n} d\left(\tilde{v}_{i j}, \tilde{v}_{j}^{*}\right), i=1,2, \ldots, m
$$

and

The normalised $\tilde{r}_{i j}$ are still triangular fuzzy numbers. 
Apak et al.

$$
d_{i}^{-}=\sum_{j=1}^{n} d\left(\tilde{v}_{i j}, \tilde{v}_{j}^{-}\right), i=1,2, \ldots, m
$$

where $d(\cdot, \cdot)$ is the distance measurement between two fuzzy numbers.

Step 7. Calculate the closeness coefficient $(C C)$ of each alternative, A: $C C$ is defined to determine the ranking order of all alternatives once the $d_{i}^{*}$ and $d_{i}^{-}$of each alternative $A_{i}(i=1,2, \ldots, m)$ has been calculated. The $C C$ of each alternative is calculated as

$$
C C=\frac{d_{i}^{-}}{d_{i}^{*}+d_{i}^{-}}, i=1,2, \ldots, m .
$$

Step 8. According to the $C C$ s, the ranking order of alternatives can be determined: Obviously, an alternative $A_{i}$ that is closer to the FPIS $\left(A^{*}\right)$ and farther from $\left(A^{-}\right)$is the best. Therefore, we can determine the ranking order of all alternatives and select the best one from a set of feasible alternatives based on the closeness coefficient.

\section{Evaluating SCEM Systems}

This application is realised for a manufacturing and distribution company. The company produces heavy construction equipment and is the distributor of one of the global Japanese brands with an important domestic market share in Turkey. The company is planning to purchase an SCEM system and identifying the most appropriate system is important due to the limited budget. According to the initial step in our methodology, a group of decision makers is gathered for the evaluation process. The group is composed of two industrial engineers, one supply chain executive, and a supply chain consultant. Those decision makers are capable of making decisions on SCEM systems due to their previous work experience and expertise in such systems.

The first activity of the decision makers is to identify SCEM system alternatives and the decision criteria. Among the SCEM system alternatives in the market, the decision makers have to choose system alternatives by examining vendors' capabilities. After a careful study, the group limited the list to seven alternatives $\left(S_{1}, \ldots S_{7}\right)$, by considering the market share of the vendors, the past records of the systems and the company needs.
Once the system alternatives are selected, decision makers have to decide on the criteria that will be used in the evaluation phase. With the contribution of the authors, a broad industry analysis and a careful inspection on the existing supply chain execution and management systems are carried by the group. Finally, the group gathers the most important and widely used criteria and secondary criteria together. The list consists of ten main criteria and sixty secondary criteria. The main criteria are Demand Management (DM), Supply Chain Optimisation (SCO), Warehouse Management System (WMS), Production and Supply Planning (PSP), Service Parts Planning (SPP), Transportation Management System (TMS), International Trade Logistics (ITL), Order Management, Supply Chain Event Management (SCE), and Supplier Relationship Management (SRM). The sixty secondary criteria are given in Appendix A together with their definitions. We refer to the SCEM system module and sub-module as the criterion and secondary criterion, respectively.

\subsection{Application of the Integrated Method}

According to our integrated decision making technique, criteria priority weights are identified with the F-AHP model and alternatives are ranked with FTOPSIS. After the approval of the decision criteria hierarchy, weights are assigned to each criterion in SCEM system selection with F-AHP in the second stage. In this phase, pairwise comparison matrices are formed to determine the criteria weights. The decision makers made individual evaluations using the scale provided in Table 2. There are four levels in the decision hierarchy structured for SCEM system evaluation. The overall goal of the decision process is determined as the selection of the best SCEM system, and it forms the first level of the hierarchy. Criteria and secondary-criteria are second and third level and the alternative systems are on the fourth level of the hierarchy, which is given in Figure 3.

Once the pairwise comparison matrices are formed and their consistency checked, the weight of each criterion is calculated with Eq. (11) and (12). The results of this calculation or the global weights are given in Table 4. The next stage involves the decision makers evaluating the selected system alternatives. The decision makers were asked to evaluate each alternative system performance according to each criterion by using the linguistic terms given in Table 3. After this 
phase, we applied F-TOPSIS methodology for ranking alternative systems given the system's scores and the FAHP weights.

As the last step, SCEM system alternatives are ranked according to their relative closeness to the ideal solution. The distances to ideal and negative-ideal solution together with $C C$ values are provided in Table 5. Based on the $C C$ values, the ranking of the alternatives in descending order is given in Table 6. It can be remarked that $C C$ values are close to each other, but System 3 has the highest value among all of the systems. System 4 has the lowest value of 0.2520 .

Table 4 Fuzzy Weights of the 60 evaluation criteria

\begin{tabular}{|c|c|c|c|c|c|}
\hline Criteria & Local weights (TFNs) & Global weights (TFNs) & Criteria & Local weights (TFNs) & Global weights (TFNs) \\
\hline$D M$ & $(0.019,0.045,0.164)$ & & $I T L$ & $(0.018,0.046,0.156)$ & \\
\hline DM1 & $(0.222,0.414,0.722)$ & $(0.004,0,019,0.118)$ & ITL1 & $(0.156,0.277,0.451)$ & $(0.003,0.013,0.070)$ \\
\hline DM2 & $(0.132,0.258,0.501)$ & $(0.003,0,012,0.082)$ & ITL2 & $(0.092,0.150,0.278)$ & $(0.002,0.007,0.043)$ \\
\hline DM3 & $(0.055,0.088,0.161)$ & $(0.001,0.004,0.026)$ & ITL3 & $(0.152,0.238,0.398)$ & $(0.003,0.011,0.062)$ \\
\hline DM4 & $(0.055,0.101,0.201)$ & $(0.001,0.005,0.033)$ & ITL4 & $(0.155,0.274,0.449)$ & $(0.003,0.013,0.070)$ \\
\hline DM5 & $(0.076,0.153,0.312)$ & $(0.001,0,007,0.051)$ & ITL5 & $(0.038,0.059,0.103)$ & $(0.001,0.003,0.016)$ \\
\hline$S C O$ & $(0.034,0.076,0.264)$ & & $O M$ & $(0.031,0.114,0.270)$ & \\
\hline $\mathrm{SCO} 2$ & $(0.119,0.190,0.302)$ & $(0.004,0.014,0.080)$ & OM2 & $(0.050,0.082,0.157)$ & $(0.002,0.009,0.042)$ \\
\hline $\mathrm{SCO} 3$ & $(0.119,0.226,0.398)$ & $(0.004,0.017,0.105)$ & OM3 & $(0.060,0.092,0.181)$ & $(0.002,0.010,0.049)$ \\
\hline $\mathrm{SCO} 4$ & $(0.065,0.105,0.208)$ & $(0.002,0.008,0.055)$ & OM4 & $(0.076,0.124,0.212$ & $(0.002,0.014,0.057)$ \\
\hline WMS & $(0.064,0.184,0.538)$ & & OM5 & $(0.068,0.110,0.198)$ & $(0.002,0.013,0.053)$ \\
\hline WMS1 & $(0.092,0.188,0.367)$ & $(0.006,0.035,0.197)$ & OM6 & $(0.096,0.211,0.411)$ & $(0.003,0.024,0.111)$ \\
\hline WMS2 & $(0.077,0.168,0.367)$ & $(0.005,0.031,0.197)$ & $S C E$ & $(0.018,0.056,0.165)$ & \\
\hline WMS3 & $(0.061,0.099,0.189)$ & $(0.004,0.018,0.102)$ & SCE1 & $(0.104,0.178,0.284)$ & $(0.002,0.010,0.047)$ \\
\hline WMS5 & $(0.042,0.078,0.188)$ & $(0.003,0.014,0.101)$ & SCE3 & $(0.041,0.061,0.096)$ & $(0.001,0.003,0.016)$ \\
\hline WMS6 & $(0.157,0.326,0.611)$ & $(0.010,0.060,0,329)$ & SCE4 & $(0.016,0.025,0.044)$ & $(0.000,0.001,0.007)$ \\
\hline$P S P$ & $(0.027,0.071,0.236)$ & & SCE5 & $(0.037,0.055,0.090)$ & $(0.001,0.003,0.015)$ \\
\hline PSP1 & $(0.194,0.306,0.461)$ & $(0.005,0.022,0.109)$ & SCE6 & $(0.088,0.144,0.227)$ & $(0.002,0.008,0.037)$ \\
\hline PSP2 & $(0.194,0.273,0.384)$ & $(0.005,0.019,0.091)$ & SCE7 & $(0.040,0.059,0.090)$ & $(0.001,0.003,0.015)$ \\
\hline PSP3 & $(0.113,0.191,0.348)$ & $(0.003,0.014,0.082)$ & SCE8 & $(0.104,0.178,0.248)$ & $(0.002,0.010,0.047)$ \\
\hline PSP4 & $(0.053,0.080,0.126)$ & $(0.001,0.006,0.030)$ & SCE9 & $(0.051,0.109,0.216)$ & $(0.001,0.006,0.036)$ \\
\hline PSP5 & $(0.050,0.077,0.122)$ & $(0.001,0.005,0.029)$ & SCE10 & $(0.040,0.056,0.094)$ & $(0.001,0.003,0.016)$ \\
\hline PSP6 & $(0.025,0.037,0.060)$ & $(0.001,0.003,0.014)$ & $S R M$ & $(0.019,0.064,0.161)$ & \\
\hline$S P P$ & $(0.060,0.178,0.511)$ & & SRM1 & $(0.029,0.048,0.093)$ & $(0.001,0.003,0.015)$ \\
\hline SPP1 & $(0.075,0.123,0.248)$ & $(0.004,0.022,0.127)$ & SRM2 & $(0.029,0.052,0.105)$ & $(0.001,0.003,0.017)$ \\
\hline SPP2 & $(0.145,0.245,0.385)$ & $(0.009,0.044,0.197)$ & SRM3 & $(0.045,0.085,0.158)$ & $(0.001,0.005,0.025)$ \\
\hline SPP3 & $(0.077,0,181,0.516)$ & $(0.004,0.025,0.158)$ & SRM4 & $(0.049,0.088,0.163)$ & $(0.001,0.006,0.026)$ \\
\hline SPP4 & $(0.139,0.239,0.379)$ & $(0.008,0.043,0.194)$ & SRM5 & $(0.074,0.151,0.303)$ & $(0.001,0.010,0.049)$ \\
\hline SPP5 & $(0.148,0.251,0.396)$ & $(0.009,0.045,0.202)$ & SRM6 & $(0.029,0.048,0.093)$ & $(0.001,0.003,0.015)$ \\
\hline TMS2 & $(0.153,0.297,0.604)$ & $(0.008,0.050,0.272)$ & SRM9 & $(0.045,0.085,0.158)$ & $(0.001,0.005,0.025)$ \\
\hline TMS3 & $(0.096,0.163,0.333)$ & $(0.005,0.027,0.150)$ & & & \\
\hline
\end{tabular}

Table 5 The distances of alternatives to positive / negative ideal solutions, the related closeness coefficients

\begin{tabular}{cccc}
\hline Alternatives & $d_{i}^{*}$ & $d_{i}^{-}$ & $C C$ \\
\hline System 1 & 0.7369 & 0.2767 & 0.2720 \\
System 2 & 0.8016 & 0.2882 & 0.2640 \\
System 3 & 0.7338 & 0.2758 & 0.2732 \\
System 4 & 0.8426 & 0.2832 & 0.2520 \\
System 5 & 0.7291 & 0.2699 & 0.2700 \\
System 6 & 0.7278 & 0.2652 & 0.2670 \\
System 7 & 0.7456 & 0.2684 & 0.2647 \\
\hline
\end{tabular}

Table 6 Ranking of alternatives

\begin{tabular}{ccc}
\hline Rank & Alternatives & $C C$ \\
\hline 1 & System 3 & 0.2732 \\
2 & System 1 & 0.2720 \\
3 & System 5 & 0.2700 \\
4 & System 6 & 0.2670 \\
5 & System 7 & 0.2647 \\
6 & System 2 & 0.2640 \\
7 & System 4 & 0.2520 \\
\hline
\end{tabular}




\subsection{Results of the integrated method and validation of the model}

Four decision makers made an evaluation with the F-AHP approach to determine criteria weights at the first phase. At the second phase, a set of seven alternatives were rated and most appropriate solution was identified with the F-TOPSIS approach. According to the F-AHP results, we are able to find the most important and the least important criteria for the selected group of experts: due to the results we can say that the most important criteria are WMS (0.064, 0.184, $0.538)$, SPP $(0.060,0.178,0.511)$, and TMS (0.054, $0.167,0.450)$ and that the least important criteria are SRM (0.019, 0.064, 0.161), DM (0.019, 0.045, 0.164), and SCE $(0.018,0.056,0.165)$. While the main criteria involved ranking, secondary criteria global weights can be ranked according to importance: TMS1 (0.015, $0.090,0.432)$, TMS2 $(0.008,0.050,0.272)$, and SCO1 $(0.011,0.039,0.216)$ and the least important secondary criteria are SCE4 $(0.001,0.003,0.0079)$ and PSP6 $(0.001,0.003,0.014)$ (see Table 4$)$. The most desirable alternative corresponds to that with the highest score; System 3 (0.2732) would be declared as the most preferable and considered a possible SCEM system. Nevertheless, the alternative System 4 is the worst choice with a score of 0.2520 (Table 6).

When testing the validity of the model, it is important that the model has not been analysed using past data, due to the unavailability of past data for the particular management case under study. This problem, however, should not be viewed as a significant shortcoming when evaluating the validity of the model. The comparison matrices that are the inputs to the suggested model are defined under known conditions. Thus, it is possible to achieve different results since different pairwise comparison matrices may be obtained at different points in time.

\section{Conclusion}

In this study, we have proposed an effective method to rate supply chain execution and management systems by integrating F-AHP and F-TOPSIS with a comprehensive set of decision criteria. A decision making group is formed by including different managerial levels with the intention of providing a more accurate and mutually acceptable solution for the company. The importance weights of criteria and the ratings of alternatives are assessed in linguistic terms. As the integrated method gives the capacity to consider the vagueness in the evaluation process of the pairwise comparison matrices, it can provide more useful and adaptable solutions. Using this fuzzified structure also gives to the decision makers the flexibility to express their opinion more openly. Our proposed method can handle the effects of dependences; it is relatively useful and makes the evaluation result more certain. As a conclusion, comprehensive research on supply chains with an integrated fuzzy method renders this method better than other fuzzy methods. F-AHP and F-TOPSIS integrated model is preferred due to the consideration of inner dependences between secondary criteria, but effectiveness of the criteria to each other should not be ignored.

The analytical model illustrated in this paper does have a few limitations. For example, the outcome of the model is dependent on the inputs provided by the decision-makers. The possibility of bias of the decisionmaker towards any particular alternative should not be ruled out while applying this model. For further research, the results of this study may be compared with the results of other fuzzy MADM methods like ORESTE, MAUT, SAW, VIKOR, ELECTRE, or PROMETHEE.

\section{References}

1. E.A. Williamson, D.K. Harrison, and M. Jordan, Information systems development within supply chain management, International Journal of Information Management, 24(5) (2004).

2. R.A. Lancioni, M.F. Smith, and H.J. Schau, Strategic Internet application trends in supply chain management, Industrial marketing Management, 32(3) (2003).

3. K.K. Hong and Y.G. Kim, The critical success factors for ERP implementation: An organizational fit perspective, Information \& Management, 40 (2002).

4. C.C. Wei, C. Chien, and M.J. Wang, An AHP-based approach to ERP system selection, International Journal of Production Economics, 96 (2005).

5. S.Y. Chou and Y.H. Chang, A decision support system for supplier selection based on a strategy aligned fuzzy SMART approach, Expert System with applications, 34 (2008).

6. S.H. Ha and R. Krishnan, A hybrid approach to supplier selection for the maintenance of a competitive supply chain, Expert Systems with Applications, 34(2) (2008). 
7. A. Gunasekaran, E.W.T. Ngai, and R.E. Mc Gaughey, Information technology and systems justification: A review for research and applications, European Journal of Operational Research 173 (2006).

8. J. Sarkis and S. Talluri, Evaluating and selecting ecommerce software and communication systems for a supply chain, European Journal of Operational Research, 159 (2004).

9. H.A. Akkermans, P.E. Yucesan, and L.N. Van Wassenhove, The impact of ERP on supply chain management: exploratory findings from a European Delphi study, European Journal of Operational Research 146(2) (2003).

10. G. Buyukozkan, C. Kahraman, and D. Ruan, A fuzzy multi-criteria decision approach for software development strategy selection, International Journal Gen. Systems, 33 (2004).

11. U. Cebeci, Fuzzy AHP based decision support system for selecting ERP systems in textile industry by using balanced scorecard, Expert Systems with Applications, 36(5) (2009).

12. A. Hakim, and H. Hakim, A practical model on controlling the ERP implementation risks, Information Systems, 35 (2010).

13. E.E. Karsak and C.O. Ozogul, An integrated decision making approach for ERP selection, Expert Systems with Applications, 36 (2009).

14. X. Liao, Y. Li, and B. Lu, A model for selecting an ERP system based on linguistic information processing, Information Systems, 32 (2007).

15. F. Su and C. Yang, Why are enterprise resource planning systems indispensable to supply chain management?, European Journal of Operational Research, 203 (2010).

16. H.R. Yazgan, S. Boran, and K. Goztepe, An ERP software selection process with using artificial neural network based on analytic network process approach, Expert Systems with Applications, 36(5) (2009).

17. N.C. Simpson and S.S. Erenguc, Modeling the order picking function in supply chain systems: Formulation, experimentation, and insights, IIE Transactions, $\mathbf{3 3}$ (2001) 119-130.

18. A. Berkelaar, C. Deert, B. Oldenkanp and S. Zhang, A primal-dual decomposition-based interior point approach to two-stage stochastic linear programming, Operations Research, 50 (2002) $904-915$.

19. B. Downs, An LP-based capable-to promise system for beef production at ConGra foods, Paper presented at the INFORMS Annual Meeting (San Jose, CA, November) (2002) 17-20.

20. Y.H. Lee, M. Gen and D.S. Hochbaum, A focused issue on supply chain management", Computers \& Industrial Engineering, 43 (2002) 1-3.

21. H. Meyr, M. Wagner and J. Rohde, Structure of advanced planning systems. In: Stadtler, H., Kilger, C. (Eds.), (Supply Chain Management and Advanced Planning-Concepts, Models Software and Case Studies, Berlin), (2002) 99-104.
22. R.C. Whitehair and A.J. Berg, Leveraging knowledge: Solving the, (problem is no longer enough. Supplement to OR/MS today 2002).

23. S. Boyson, T. Corsi and A. Verbraeck, The e-supply chain portal: a core business model, Transportation Research Part E, 39 (2003) 175-192.

24. A.C. Caputo, P.M. Pelagagge and F. Scacchia, Integrating transport systems in supply chain management software tools, Industrial Management \& Data Systems, 103(7) (2003) 503-515.

25. B. Fleischmann and H. Meyr, Customer orientation in advanced planning systems, In: Dyckhoff, H., Lackes, R., Reese, J. (Eds.), Supply Chain Management and Reverse Logistics, Berlin, (2003) 297-321.

26. B.S. Sahay and A.K. Gupta, Development of software selection criteria for supply chain solutions", Industrial Management \& Data Systems, 103(2) (2003) 97-110.

27. H. Stadtler, Supply chain management and advanced planning - basics, overview and challenges, European Journal of Operational Research, 163 (2004) 575-588.

28. S.M. Disney, M.M. Naim and A. Potter, Assessing the impact of e-business on supply chain dynamics, International Journal of Production Economics, 89(2) (2004) 109 -118.

29. C. Arbib and F. Marinelli, Integrating process optimization and inventory planning in cutting-stock with skiving option: An optimization model and its application, European Journal of Operational Research, 163(3) (2003) $617-630$.

30. N. Dellaert and J. Jeunet, An alternative to safety stock policies for multi-level rolling schedule MRP problems, European Journal of Operational Research, 163(3) (2005) $751-768$.

31. P. Helo and B. Szekely, An analysis of software solutions for supply chain co-ordination", Industrial Management \& Data Systems, 105(1) (2005) 5-18.

32. C. Nilsen and C. Larsen, An analytical study of the $\mathrm{Q}(\mathrm{s}, \mathrm{S})$ policy applied to the joint replenishment problem, European Journal of Operational Research, 163(3) (2005) 721 - 732.

33. J.A. Persson and M. Göthe-Lundgren, Shipment planning at oil refineries using column generation and valid inequalities", European Journal of Operational Research, 163(3) (2005) 631 - 652.

34. J.M. Spitter, C.A.J. Hurkens, A.G. Kok, J.K. Lenstra and E.G. Negenman, Linear programming models with planned lead times for supply chain operations planning, European Journal of Operational Research, 163(3) (2005) 706 - 720.

35. S. Lancester, D.C. Yen, and C.Y. Ku, E-supply chain management: an evaluation of current web initiatives, Information Management \& Computer Security, 14(2) (2006) 167-184.

36. M. Karkkainen, S. Laukkanen, S. Sarpola and K. Kemppainen, Roles of interfirm information systems in supply chain management", International Journal of 
Physical Distribution \& Logistics Management, 37(4) (2007) 264-286.

37. C.W. Chang, C.R. Wu, C.T., Lin, and H.L. Lin, Evaluating digital video recorder using analytic hierarchy and analytic network process, Information Sciences, 177(16) (2007).

38. X. Xu, A note on the subjective and objective integrated approach to determine attribute weights, European Journal of Operation Research, 156 (2004).

39. C.H. Yeh and Y.H. Chang, Modeling subjective evaluation for fuzzy group multi criteria decision making, European Journal of Operational Research 194 (2)(2009).

40. J. Lu, G. Zhang, and D. Ruan, Intelligent multi-criteria fuzzy group decision-making for situation assessments, Soft Computing 12 (2008).

41. I. Ertugrul and N. Karakasoglu, Performance evaluation of Turkish cement firms with fuzzy analytic hierarchy process and TOPSIS methods, Expert Systems and Applications, 36(1) (2009).

42. H.Y. Lin, P.Y. Hsu, and G.J. Sheen, A fuzzy based decision making procedure for data warehouse system selection, Expert Systems with Applications, 44 (2006).

43. A.S. Jadhav and R.M. Sonar, Evaluating and selecting software packages: A review, Information and Software Technology, 51 (2009).

44. T. L. Saaty, The analytic hierarchy process, McGrawHill Company (New York, 1980).

45. F.T. Bozbura, A. Beskese, and C. Kahraman, Prioritization of human capital measurement indicators using fuzzy AHP, Expert Systems with Applications, 32(4) (2007).

46. C.W. Chang, C.R. Wu, and H.C. Chen, Using expert technology to select unstable slicing machine to control wafer slicing quality via fuzzy AHP, Expert Systems with Applications, 34(3) (2008).

47. R. Aull-Hyde, S. Erdogan, and J.M. Duke, An experiment on the consistency of aggregated comparison matrices in AHP, European Journal of Operational Research, 171(1) (2006).

48. L. Mikhailov, A fuzzy approach to deriving priorities from interval pairwise comparison judgments, European Journal of Operational Research, 159 (2004).

49. V.B. Kreng and C.Y. Wu, Evaluation of knowledge portal development tools using a fuzzy AHP approach: The case of Taiwanese stone industry, European Journal of Operational Research, 176 (2007).

50. A.H.I. Lee, W.C. Chen, and C.J. Chang, A fuzzy AHP and BSC approach for evaluating performance of IT department in the manufacturing industry in Taiwan, Expert Systems with Applications, 34 (2008).

51. O. Cakir and M.S. Canbolat, A web-based decision support system for multi-criteria inventory classification using fuzzy AHP methodology, Expert Systems with Applications, 35(3) (2008).

52. H.P. Fu, P. Chao, T.H. Chang, and Y.S. Chang, The impact of market freedom on the adoption of third-party electronic marketplaces: A fuzzy AHP analysis, Industrial Marketing Management, 37(6) (2008).

53. S. Opricovic and G.H. Tzeng, Compromise solution by MCDM methods: A comparative analysis of VIKOR and TOPSIS, European Journal of Operational Research, 156(2) (2004).

54. C. Kahraman, G. Buyukozkan, and N.Y. Ates, A two phase multi-attribute decision-making for new product introduction, Information Sciences, 177 (2007).

55. H. Deng, C.H. Yeah, and R.J. Willis, Inter-company comparison using modified TOPSIS with objective weights, Computers \& Operations Research, 27(10) (2000).

56. C.H. Yeh, H. Deng, and Y.H. Chang, Fuzzy multicriteria analysis for performance evaluation of bus companies, European Journal of Operational Research, 126(3) (2000).

Appendix A. Modules and Sub-modules Definition

\begin{tabular}{|c|c|c|}
\hline Code & Criteria and secondary criteria & Definition \\
\hline DM & Demand Management & $\begin{array}{l}\text { Identifying and creating demand, modelling, and collaborating, with the network of } \\
\text { trading partners. }\end{array}$ \\
\hline DM1 & Promotion Planning & $\begin{array}{l}\text { Allow organisations to plan promotions with their trade collaborators, including } \\
\text { simulating, executing, promotion performance. }\end{array}$ \\
\hline DM2 & Forecasting & Gathers all data that can impact the ultimate demand placed upon the supply chain. \\
\hline DM3 & Life Cycle Planning & Provides the ability to view sell-in and sell-through point of sale data. \\
\hline DM4 & Consensus and Collaborative Planning & $\begin{array}{l}\text { Allow the ability for joint sharing and modelling of demand supply gaps between } \\
\text { trading partners. }\end{array}$ \\
\hline DM5 & Event Planning & $\begin{array}{l}\text { Product launches, special media and advertising, promotional events, or new store } \\
\text { openings need fine planning to be successful. }\end{array}$ \\
\hline SCO & Supply Chain Optimisation & $\begin{array}{l}\text { To design an optimal physical supply chain network and solve long-term strategic } \\
\text { problems. }\end{array}$ \\
\hline SCO1 & Network Optimisation & Performed yearly or whenever major shifts in the supply chain occur. \\
\hline $\mathrm{SCO} 2$ & Route and Territory Design & Optimal of regional and geographic logistics strategies to support local markets. \\
\hline
\end{tabular}




\begin{tabular}{|c|c|c|}
\hline $\mathrm{SCO3}$ & Fleet Planning, Routing and Scheduling & $\begin{array}{l}\text { Tactically to determine fleet requirements for a specific timeframe. Allow user to } \\
\text { determine if they are getting the most expeditious service. }\end{array}$ \\
\hline SCO4 & Inventory Optimisation for Supply Network & $\begin{array}{l}\text { Allow the organisation to create an inventory supply network from multi-tier or n-tier } \\
\text { suppliers through to multi-channel to customers. }\end{array}$ \\
\hline WMS & Warehouse Management System (WMS) & $\begin{array}{l}\text { Provide database and user-level tools in order for a company to optimise its storage } \\
\text { facilities. }\end{array}$ \\
\hline WMS1 & Warehouse and Bin Configuration & $\begin{array}{l}\text { Communication between the warehouse and the office slows down the multi-bin } \\
\text { process. }\end{array}$ \\
\hline WMS2 & Inventory Control for Warehouses & Tracks product usage and costs, and maintains inventory at optimum levels. \\
\hline WMS3 & Receiving and Quality Control & $\begin{array}{l}\text { Enforce the quality control process through a series of system-directed prompts to } \\
\text { ensure that product is handled correctly. }\end{array}$ \\
\hline WMS4 & Put-away, Picking & Making the association between product receipts and storage locations. \\
\hline WMS5 & Cycle Count & Procedure that a small subset of inventory is counted on any given day. \\
\hline WMS6 & Packing and Shipping & $\begin{array}{l}\text { Association between an order and series of orders and required packing materials and } \\
\text { documentation. }\end{array}$ \\
\hline PSP & Production and Supply Planning & $\begin{array}{l}\text { Allows the solutions to solve for simulation issues extremely quickly, with very large } \\
\text { arrays. }\end{array}$ \\
\hline PSP1 & $\begin{array}{l}\text { Long-term Sales, Operations and Capacity } \\
\text { Planning }\end{array}$ & $\begin{array}{l}\text { Allow simulation and scenario building, which can be created even in joint meeting } \\
\text { sessions. }\end{array}$ \\
\hline PSP2 & Operational Planning & $\begin{array}{l}\text { Aggregate or disaggregate multilevel plans, so the concept of a master production } \\
\text { system. }\end{array}$ \\
\hline PSP3 & Procurement Collaboration & $\begin{array}{l}\text { Dynamical collaborates with the supplier to create demand, place orders, and get a } \\
\text { systemic response. }\end{array}$ \\
\hline PSP4 & BOM, Design and Building & $\begin{array}{l}\text { Define products as they are designed, as they are ordered, as they are built, or as they } \\
\text { are maintained. }\end{array}$ \\
\hline PSP5 & Routing Design and Optimization & $\begin{array}{l}\text { Provide the intelligence that takes a collection of physical links and transforms them } \\
\text { into a network that enables packets to travel. }\end{array}$ \\
\hline PSP6 & Cycle Time Analysis and Optimization & $\begin{array}{l}\text { Includes process time, during which a unit is acted upon to bring it closer to an output, } \\
\text { and delay time }\end{array}$ \\
\hline SPP & Service Parts Planning & $\begin{array}{l}\text { Enable the creation of service centres, depots, and the positioning of the appropriate } \\
\text { inventory and workforce capacity. }\end{array}$ \\
\hline SPP1 & Parts and Service Planning & Deals with the creation and replenishment of a supply network for service operations. \\
\hline SPP2 & Service Delivery and Execution & Integrate in order to handle the management of depot responsiveness \\
\hline SPP3 & Workforce Optimisation & $\begin{array}{l}\text { Used for determining the right skill mix and location of personnel to support service } \\
\text { demands. }\end{array}$ \\
\hline SPP4 & Transportation Planning & Has a significant role to play in the service supply chain. \\
\hline SPP5 & Reverse Logistics & Pickup of parts for delivery to third-party locations for repair. \\
\hline TMS & $\begin{array}{l}\text { Transportation Management System } \\
\text { (TMS) }\end{array}$ & Provide the basic components of a shared information system to support. \\
\hline TMS1 & System Definition and Implementation & $\begin{array}{l}\text { Include tools and applications to enable the user to create profiles for all contracts, } \\
\text { and trade lanes for inter-modal and multi-leg moves. }\end{array}$ \\
\hline TMS2 & Required Features and Functions & $\begin{array}{l}\text { Enable users to perform all key functions when planning, executing and analysing } \\
\text { transportation movements. }\end{array}$ \\
\hline TMS3 & $\begin{array}{l}\text { System Analysis and Reporting for } \\
\text { Transportation }\end{array}$ & $\begin{array}{l}\text { Enable the user to track carrier performance ad-hoc as well as through structured } \\
\text { queries and reports. }\end{array}$ \\
\hline ITL & International Trade Logistics (ITL) & $\begin{array}{l}\text { Enables organisations to make trade decisions by streamlining, accelerating, and } \\
\text { integrating complex import and export processes. }\end{array}$ \\
\hline ITL1 & Advanced Collaboration & $\begin{array}{l}\text { The data model should take into account the different roles of all participants and } \\
\text { manage these through a set of rule-based processes. }\end{array}$ \\
\hline ITL2 & Product Description & $\begin{array}{l}\text { Includes a description of the product and defines all key characteristics of the any } \\
\text { given product. }\end{array}$ \\
\hline ITL3 & Compliance Model & $\begin{array}{l}\text { A data model that considers all these factors, maintaining the inter-relationship at the } \\
\text { product, trading partner, and logistics level. }\end{array}$ \\
\hline ITL4 & Logistics & $\begin{array}{l}\text { Provide the user with a set of tools to establish rates, routes, and contracts for } \\
\text { preferred transportation modes and providers. }\end{array}$ \\
\hline ITL5 & Commerce & $\begin{array}{l}\text { Enable to obtain an estimated total cost of goods sold as well as a final cost of goods } \\
\text { sold, to highlight any variances or discrepancies. }\end{array}$ \\
\hline $\mathbf{O M}$ & Order Management & $\begin{array}{l}\text { To implement software that enables business processes and data integration in } \\
\text { heterogeneous business and systems environments. }\end{array}$ \\
\hline OM1 & Order Promising & $\begin{array}{l}\text { Responsible for order administrative functions such as CRM, quoting, and other } \\
\text { administrative functions. }\end{array}$ \\
\hline OM2 & Inventory Analysis for Order & $\begin{array}{l}\text { Determine how much inventory you should hold, and when you should place } \\
\text { inventory orders. }\end{array}$ \\
\hline
\end{tabular}




\begin{tabular}{|c|c|c|}
\hline OM3 & Sourcing Management & $\begin{array}{l}\text { Attribute of a distributed order fulfilment system is the ability to do multi-stage } \\
\text { sourcing and assembly. }\end{array}$ \\
\hline OM4 & (Manufacturing) Order Tracking & Allows online tracking of any product among all manufacturing process. \\
\hline OM5 & $\begin{array}{l}\text { Inbound and Assembly Coordination or Multi- } \\
\text { site Staging }\end{array}$ & $\begin{array}{l}\text { Many orders are sourced and built by a network of partners. Frequently, notification } \\
\text { of cancellations does not occur. }\end{array}$ \\
\hline OM6 & Shipment Tracking & $\begin{array}{l}\text { Through this online tracking facility, you can get real time status information on your } \\
\text { shipment. }\end{array}$ \\
\hline SCE & Supply Chain Event Management & $\begin{array}{l}\text { Designed to monitor, notify, analyse, measure, and control business process and } \\
\text { execution types of activities. }\end{array}$ \\
\hline SCE1 & Metrics and Formula Library for Data & $\begin{array}{l}\text { Data required for calculating metrics should be continuously collected in parallel with } \\
\text { process assessment and improvement. }\end{array}$ \\
\hline SCE2 & Rules and Alerts Hierarchy Setup for Events & $\begin{array}{l}\text { A hierarchy set up lets you group content into a hierarchy that makes content easier to } \\
\text { find. }\end{array}$ \\
\hline SCE3 & $\begin{array}{l}\text { Data Drilling, Aggregating, and Exploding for } \\
\text { Data mining }\end{array}$ & $\begin{array}{l}\text { Substitute or replace the traditional business intelligence system by providing real- } \\
\text { time views of data, working off a dynamic database. }\end{array}$ \\
\hline SCE4 & Price Deviation Analysis & $\begin{array}{l}\text { Costs, price deviations are identified and presented real-time in the deviation monitor, } \\
\text { giving the finance depart. a unique tool to act on. }\end{array}$ \\
\hline SCE5 & Engineering Change Order Tracking & $\begin{array}{l}\text { Efficiently manage design review and approval for multiple types of engineering } \\
\text { change orders across the extended product team. }\end{array}$ \\
\hline SCE6 & Inventory Shortage Analysis for Supply & Offers some inventory prediction and/or management capabilities. \\
\hline SCE7 & Quality Data Analysis & Take account every point of data significance in analysis period. \\
\hline SCE8 & Equipment, Breakdown Analysis & $\begin{array}{l}\text { The reliability analysis section of module may be used to guide you towards setting } \\
\text { the correct tasks. }\end{array}$ \\
\hline SCE9 & Demand Volatility Analysis & $\begin{array}{l}\text { Determining initial demand at the start of a dispatch interval used to launch the } \\
\text { demand forecast. }\end{array}$ \\
\hline SCE10 & Analysis of Logistics inefficiencies & $\begin{array}{l}\text { Analysing out inefficiencies from logistics is a specialized endeavour that requires a } \\
\text { clear overview of every link in the chain. }\end{array}$ \\
\hline SCE11 & Risk Management & $\begin{array}{l}\text { Attempting to identify and then manage threats that could severely influence or bring } \\
\text { down the organisation. }\end{array}$ \\
\hline SRM & Supplier Relationship Management (SRM) & $\begin{array}{l}\text { Includes interactions with the supply base throughout the full lifecycle of processes } \\
\text { from design through to fulfilment. }\end{array}$ \\
\hline SRM1 & $\begin{array}{l}\text { Collaboration in Design and Requirements } \\
\text { Identification }\end{array}$ & $\begin{array}{l}\text { Provide collaboration tools that allow suppliers to participate as a member of the team } \\
\text { that sets requirements and targets. }\end{array}$ \\
\hline SRM2 & Commodity Management & $\begin{array}{l}\text { Tools for analysing global spend across many dimensions are needed to come up with } \\
\text { optimum sourcing decisions. }\end{array}$ \\
\hline SRM3 & Supplier Management & $\begin{array}{l}\text { Enables finding and qualifying the best supplier, maintaining the list of approved } \\
\text { suppliers, maintaining and accessing a database. }\end{array}$ \\
\hline SRM4 & $\begin{array}{l}\text { RFx (Request For } \mathrm{x} \text { ) and Contract } \\
\text { Management }\end{array}$ & $\begin{array}{l}\text { Tools for creating and distributing a request for information, request for proposal, or } \\
\text { request for quotation. }\end{array}$ \\
\hline SRM5 & Catalogue Management for Product & $\begin{array}{l}\text { To import data from the supply base, this is generally stored in a vast variety of } \\
\text { formats and using a variety of different semantics. }\end{array}$ \\
\hline SRM6 & MRP or Requisition-Driven Procurement & $\begin{array}{l}\text { Allow users to buy from catalogues, automatically route requisitions for approval, } \\
\text { provide tracking of approval status, generate and send purchase orders. }\end{array}$ \\
\hline SRM7 & Price, Discounts, Cost Management & $\begin{array}{l}\text { Provides functions to monitor and analyse purchase price variance, which is the key to } \\
\text { controlling costs. }\end{array}$ \\
\hline SRM8 & Return Management & $\begin{array}{l}\text { For situations where components are being returned to and repaired or replaced by } \\
\text { suppliers. }\end{array}$ \\
\hline SRM9 & $\begin{array}{l}\text { Quality and Engineering Change Order } \\
\text { Management }\end{array}$ & $\begin{array}{l}\text { Quality focuses primarily on supporting the certification process for components, as } \\
\text { well as managing the corrective action process. }\end{array}$ \\
\hline
\end{tabular}

